\title{
Fast acting nervous regulation of immunoglobulin A secretion from isolated perfused porcine ileum
}

\author{
P T Schmidt, L Eriksen, M Loftager, T N Rasmussen, J J Holst
}

\begin{abstract}
Background-The intestinal mucosa harbours a large number of nerve fibres and also plasma cells, providing the anatomical basis for studies of neuroimmune interactions.

Aims-To study the effect of different neurotransmitters and electrical stimulation of the extrinsic intestinal nerves on secretion of immunoglobulin A (IgA).

Methods-IgA was measured, using a specific ELISA, in the luminal and venous effluent from isolated vascularly perfused porcine ileal segments with preserved extrinsic nerve supply.

Results-Infusion of several neuropeptides stimulated IgA output. Somatostatin $\left(10^{-8} \mathrm{M}\right)$ stimulated IgA secretion in the luminal effluent from $46.6(14.3)$ to 79.3 (19.0) $\mu \mathrm{g} / 5 \mathrm{~min}$ and increased the venous output to $148.3(23.0) \%(n=6)$ of basal output, whereas noradrenaline $\left(10^{-6} M\right)$ inhibited the secretion (to 49.2 (6.5)\% of basal output, $n=6)$. Electrical stimulation of the mixed extrinsic nerves supplying the intestinal segment had no effect by itself. However, electrical stimulation during infusion of $\alpha$ adrenergic blockers or coinfusion of both $\alpha$ adrenergic and muscarinic blockers resulted in an immediate and significant increase in $\operatorname{IgA}$, an effect that was abolished by nicotinic blockade.
\end{abstract}

Conclusion-The extrinsic nerve supply to the intestine could be involved in fast acting regulation of mucosal immune functions.

(Gut 1999;45:679-685)

Keywords: neuroimmunology; enteric nervous system; neuropeptide; parasympathetic; sympathetic

Interactions between the nervous system and the immune system have been described in a large number of studies and have been identified at different levels ranging from cellular studies to human studies. Thus, it has been shown that stress can influence immunological functions (found in both animals and humans), ${ }^{1}$ that neuropeptides have effects on different immune cells in vitro, ${ }^{2-6}$ that receptors for neuropeptides are present on immune cells, ${ }^{78}$ and that peptidergic nerve fibres traverse lymphoid tissue. ${ }^{79}$ Psychological and environmental factors may potentially influence immune functions through the central nervous system regulating the immune system via autonomic nerves. ${ }^{10}$
The structural organisation of the intestinal mucosa provides anatomical support for neuroimmune interactions. The intestinal lamina propria is densely innervated with nerve fibres containing different neurotransmitters including noradrenaline, acetylcholine, and neuropeptides. ${ }^{11}$ A large number of immune cells, including immunoglobulin producing plasma cells, are also present in the intestinal lamina propria. Distances as short as $20-200$ $\mathrm{nm}$ have been reported between somatostatinergic nerve fibres and lymphocytes and plasma cells in the intestinal mucosa. ${ }^{9}$

Secretion of immunoglobulin A ( $\operatorname{IgA}$ ) has previously been shown to be augmented in rat intestine in vivo by infusion of cholecystokinin and pilocarpine, ${ }^{12}{ }^{13}$ but the effect of direct stimulation of the nerves supplying the intestine on immunoglobulin secretion has, to our knowledge, not been studied before.

We have previously shown that electrical stimulation of the extrinsic nerves to the isolated porcine small intestine results in release of various neuropeptides including substance $\mathrm{P}$ (SP), neurokinin A (NKA), and vasoactive intestinal polypeptide (VIP).${ }^{15}{ }^{15} \mathrm{We}$ therefore decided to use the same model to study the effects of electrical nerve stimulation and infusion of neurotransmitters on the release of the major intestinal immunoglobulin, IgA, to both the lumen and the venous effluent.

\section{Methods}

PERFUSION EXPERIMENTS

Pigs, strain LYY, weighing $14-16 \mathrm{~kg}$, that were fasted overnight with free access to water, were anaesthetised without premedication with $2.5 \%$ halothane in $\mathrm{N}_{2} \mathrm{O} / \mathrm{O}_{2}$ for induction, followed by intravenous infusion of chloralose (50 mg/kg, Merck, Darmstadt, Germany). Permission to conduct animal experiments, which conformed to the Danish legislation on animal experimentation (1987), was granted from the National Superintendence for Experimental Animals.

A $60-90 \mathrm{~cm}$ segment of the mid ileum was isolated together with the supplying mesenteric artery and vein (fig 1). During the isolation, great care was exercised to preserve all visible nerve fibres to the segment; usually most fibres formed a dense network around the supplying artery. After positioning of catheters in the artery and the vein, the preparation was excised and placed in a previously described, single pass perfusion system ${ }^{16}$ and perfused at a

Abbreviations used in this paper: CGRP, calcitonin gene related peptide; IgA, immunoglobulin A; NKA, neurokinin A; SP, substance P; VIP, vasoactive intestinal polypeptide. 


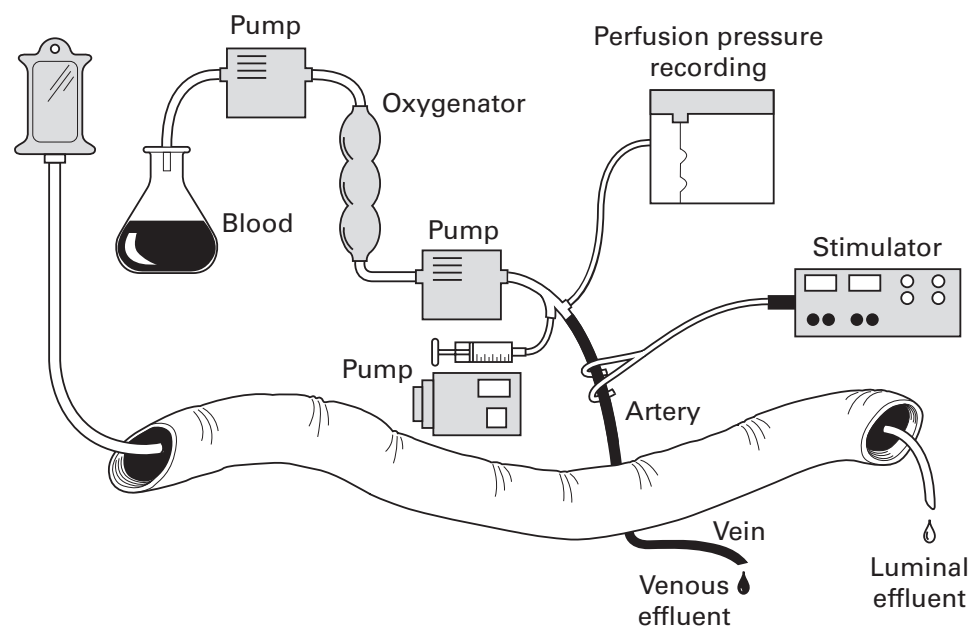

Figure 1 Illustration of the isolated vascularly perfused porcine ileum placed in a thermostatically controlled bath $\left(37^{\circ} \mathrm{C}\right)$. The segment receives perfusion medium containing oxygenated erythrocytes through the ileal artery. Perfusion flow is kept constant and the perfusion pressure measured continuously. The extrinsic nerves to the segment situated around the artery can be electrically stimulated. The lumen of the segment is perfused at a constant rate (not illustrated) and both luminal effluent and the venous effluent are collected. saturation, $\mathrm{pH}$, standard bicarbonate, $\mathrm{PO}_{2}$, and $\mathrm{PCO}_{2}$ were measured at regular intervals using the ABL-II automatic equipment (Radiometer, Copenhagen, Denmark). Because of the presence of the erythrocytes, indomethacin (Confortid, Dumex, Copenhagen, Denmark) was added to a concentration of $5 \mathrm{mg} / \mathrm{l}$ perfusate to prevent formation of prostaglandins in the perfusate. The venous effluent was collected for one minute periods. Samples of the venous and the luminal effluent were collected in polyethylene tubes (Minisorb, Nunc, Roskilde, Denmark) and immediately centrifuged at $4^{\circ} \mathrm{C}$. The supernatants were decanted and stored at $-20^{\circ} \mathrm{C}$ until enzyme linked immunosorbent assay (ELISA) measurements for porcine IgA and somatostatin.

\section{EXPERIMENTAL PROTOCOL}

After a 30 minute period, intra-arterial infusions of acetylcholine, noradrenaline (both $10^{-6}$ $\mathrm{M})$, capsaicin $\left(10^{-5} \mathrm{M}\right), \mathrm{SP}, \mathrm{NKA}$, somatostatin, calcitonin gene related peptide (CGRP), and VIP (all $10^{-8} \mathrm{M}$ ) were performed in random order. The nerves were stimulated electrically with square wave impulses of 10 $\mathrm{mA}$ and 4 milliseconds of duration with a frequency of $8 \mathrm{~Hz}$. Nerve stimulation was repeated in nine experiments during infusion of atropine $\left(10^{-6} \mathrm{M}\right)$, in seven experiments in the presence of phentolamine $\left(10^{-5} \mathrm{M}\right)$, and in 16 experiments in the presence of both atropine and phentolamine; in nine of the experiments, the nerves were stimulated in the presence of hexamethonium $\left(3 \times 10^{-5} \mathrm{M}\right)$ in addition to atropine and phentolamine. Infusion of the different blockers started at least 10 minutes before nerve stimulation. All stimulations (nerve stimulations and peptide infusions) were separated by rest periods of at least 10 minutes.

\section{DRUGS}

Synthetic SP, VIP, and somatostatin were obtained from Peninsula Laboratories (Merseyside, UK). Porcine CGRP was synthesised according to Rasmussen et al. ${ }^{18}$ Atropine and noradrenaline were from DAK Laboratories (Copenhagen, Denmark), phentolamine (Regitin) from Ciba-Geigy (Basel, Switzerland), and capsaicin, acetylcholine, and hexamethonium from Sigma (St Louis, Missouri). All drugs were infused by means of precision pumps attached to the arterial line, in amounts calculated to yield final perfusate concentrations as indicated.

\section{IgA MEASUREMENT}

IgA concentrations were measured in a sandwich ELISA. ${ }^{19}$ In short, ELISA plates (MaxiSorb, Nunc, Denmark) were coated with goat antiporcine IgA antibodies (Kirkegaard and Perry) diluted $1 / 2500$ in $0.05 \mathrm{M}$ carbonate buffer, $\mathrm{pH} 9.2(100 \mu \mathrm{l} /$ well $)$. Plates were blocked using $0.5 \%$ normal rabbit serum and washed using phosphate buffered saline containing $0.05 \%$ Tween 20 (PBS-T).

Luminal or venous samples (100 $\mu \mathrm{l} /$ well) were added to the plates, in twofold dilutions in PBS-T, along with a calibrator of purified 
A
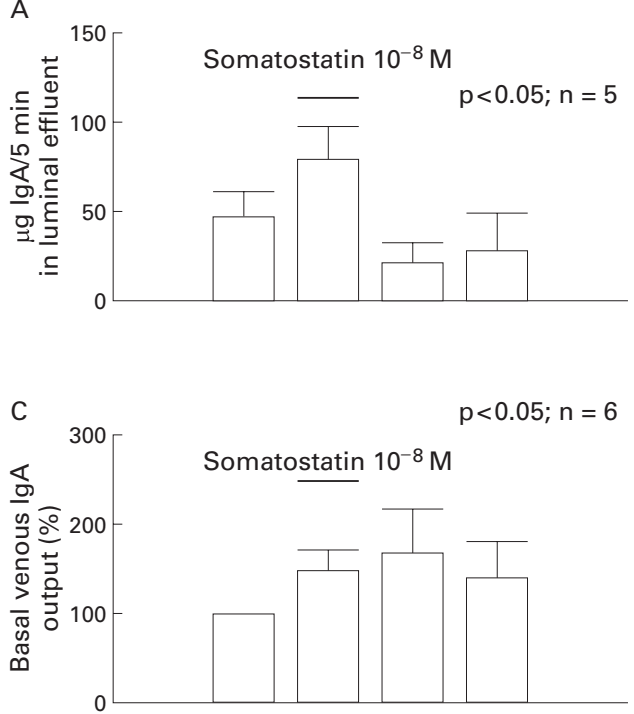

B
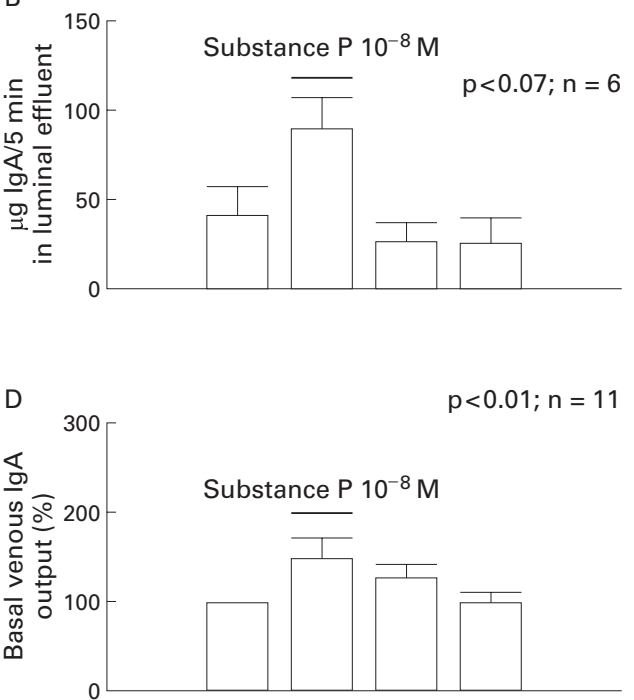

Figure 2 Effects of infusions of substance P and somatostatin (both $10^{-8} \mathrm{M}$ ) on release of IgA to the lumen (upper panel) and the venous effluent (lower panel). Results expressed as mean (SEM). The four bars represent the prestimulatory, stimulatory, and two poststimulatory five minute periods.

dimeric $\operatorname{IgA}(1000,500,250,250,62.5,31.3$, $15.6 \mathrm{ng} / \mathrm{ml})$. The secondary antibody was peroxidase labelled goat antiporcine IgA antibodies (Kirkegaard and Perry) diluted 1/1000, and the enzyme substrate was 1,2 phenylenediamine dihydrochloride (OPD, Dako, Glostrup, Denmark) in citric acid, $\mathrm{pH}$ 5.0, containing $0.0125 \% \quad \mathrm{H}_{2} \mathrm{O}_{2}$. The enzyme reaction was stopped using $1 \mathrm{M}$ sulphuric acid, and absorbancies were read at $492 \mathrm{~nm}$. The concentration of IgA in samples was determined by comparison of the absorbancies of samples in different dilutions with the absorbancies of the known concentrations of the calibrators of purified $\operatorname{IgA.}$

Dimeric IgA was purified from porcine raw milk using a Minileak agarose column (KemEn-Tec, Copenhagen, Denmark) coated with monoclonal antibodies against secretory component, kindly provided by Christopher Stokes (University of Bristol, UK). Purity was tested by sodium dodecyl sulphate polyacrylamide gel electrophoresis (SDS-PAGE).

\section{SOMATOSTATIN MEASUREMENT}

Somatostatin was measured as described, ${ }^{20}$ using standards of synthetic somatostatin 14 with an antiserum (code no. 1758) that cross reacts equally well with somatostatin 14 and somatostatin 28 . The sensitivity was below 2 $\mathrm{pmol} / \mathrm{l}$ and the intra-assay coefficient of variation below $5 \%$.

\section{STATISTICAL EVALUATION}

The IgA output in the luminal effluents is expressed as $\mu \mathrm{g} / 5 \mathrm{~min}$, calculated as the total volume of luminal output multiplied by the IgA concentration. The effects of the different stimuli on IgA and somatostatin output in the venous effluents are expressed as percentage of the prestimulatory level. The statistical significance of changes induced by the different stimuli on $\operatorname{IgA}$ release, somatostatin release, and perfusion pressure was evaluated by Friedman's analysis of variance, comparing the pre- stimulatory period, the stimulation period, and the two poststimulatory periods. Differences resulting in $\mathrm{p}$ values less than 0.05 were considered significant.

\section{Results}

IgA RELEASE

The basal release of IgA from the ileal segment in the luminal effluent was 40.3 (13.8) $\mu \mathrm{g} / 5$ min (mean (SEM), $\mathrm{n}=7$ ), ranging from 2.7 to $97.6 \mu \mathrm{g} / 5 \mathrm{~min}$, and in the venous effluent, 0.25 (0.06) $\mu \mathrm{g} / 5 \mathrm{~min}(\mathrm{n}=9)$, ranging from 0.05 to $1.15 \mu \mathrm{g} / 5 \mathrm{~min}$.

The effect of different stimuli on the luminal release of IgA was measured in effluent expelled in the distal part of the ileal segment. The effects of somatostatin and SP, both strong stimulators of motility in the porcine small intestine, on IgA secretion, were measured in both the luminal and venous effluent. The other stimuli were evaluated in the venous effluent only. Somatostatin $\left(10^{-8} \mathrm{M}\right)$ infusion increased the luminal output of IgA from 46.6 (14.3) to $79.3(19.0) \mu \mathrm{g} / 5 \mathrm{~min}(\mathrm{p}=0.018, \mathrm{n}=5)$. In these experiments, the concentration of $\operatorname{IgA}$ in the luminal effluent was $0.87(0.27) \mu \mathrm{g} / \mathrm{ml}$ before somatostatin infusion, $1.21(0.40)$ during, and $1.22(0.30)$ in the period after $(p=0.015)$. In the venous effluent, the output of IgA increased to $150.2(22.9) \% \quad(\mathrm{p}=0.016$, $\mathrm{n}=6$ ) of basal output during infusion of somatostatin. In response to infusion of SP $\left(10^{-8} \mathrm{M}\right)$, the luminal output of IgA increased from 41.5 (16.2) to $90.4(17.8) \mu \mathrm{g} / 5 \mathrm{~min}(\mathrm{p}=0.067, \mathrm{n}=6)$. The concentration of IgA in the luminal effluent was $0.80(0.27), 0.88(0.30)$, and 1.20 $(0.29) \mu \mathrm{g} / \mathrm{ml}$ in the periods before, during, and after infusion of SP $10^{-8} \mathrm{M}(\mathrm{p}=0.11)$. The venous output increased to 148.3 (23.0)\% $(\mathrm{p}=0.003, \mathrm{n}=11)$ of basal output during infusion of SP at $10^{-8} \mathrm{M}$ (fig 2).

NKA and CGRP (both $10^{-8} \mathrm{M}$ ) both stimulated venous release of IgA (to 161.7 (17.7)\% $(\mathrm{p}=0.029, \mathrm{n}=7)$ and $151.0(36.6) \%(\mathrm{p}=0.034$, $\mathrm{n}=7$ ) of basal release, respectively), whereas 


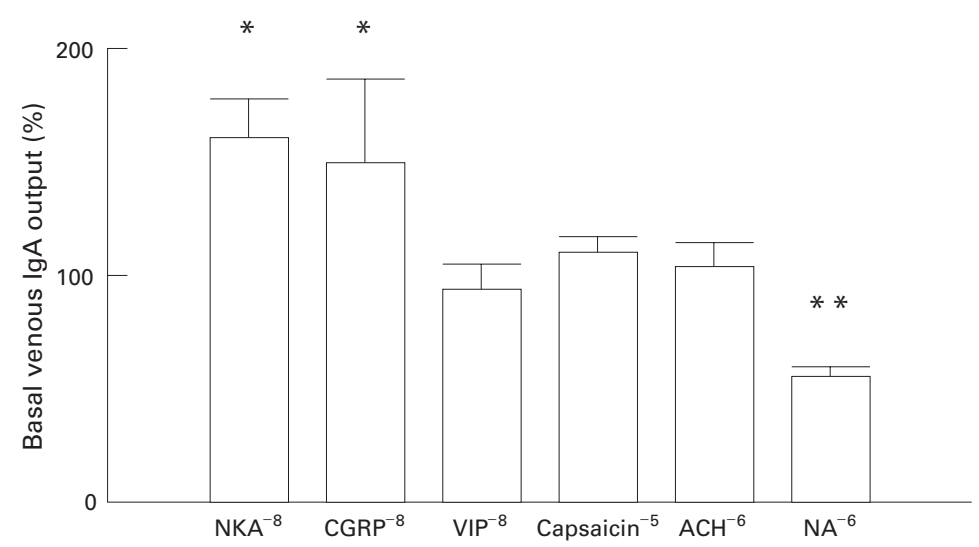

Figure 3 Effects of neurokinin A (NKA), calcitonin gene related peptide (CGRP), vasoactive intestinal polypeptide (VIP), capsaicin, acetylcholine (ACH), and noradrenaline (NA) on the release of IgA to the venous effluent. Results expressed as mean (SEM). ${ }^{\star} p<0.05,{ }^{\star *} p<0.01$. increased the venous IgA output to 125.4 (19.2)\% of basal output $(\mathrm{p}=0.08, \mathrm{n}=9)$, and a significant increase in IgA output to the venous effluent was seen in response to electrical nerve stimulation during infusion of $10^{-5} \mathrm{M}$ phentolamine (to 138.2 (19.2)\% of basal output, $\mathrm{p}=0.004, \mathrm{n}=7)$. During infusion of both atropine and phentolamine, electrical nerve stimulation increased IgA output (to 136.5 (15.2)\% of basal output, $\mathrm{p}=0.008, \mathrm{n}=16$ ), but this effect was abolished by the addition of $3 \times$ $10^{-5} \mathrm{M}$ hexamethonium (IgA output 104.8 (10.3)\% of basal output, n=9; fig 4). Generally, the stimulatory effect of the stimuli continued into the first five minute poststimulatory period.

\section{SOMATOSTATIN RELEASE}

Figure 5 shows release of somatostatin during electrical nerve stimulation. Electrical nerve stimulation had no significant effect on somatostatin release, although a tendency to a poststimulatory increase was seen $(p=0.08, n=13)$. Nerve stimulation during infusion of atropine also tended to increase somatostatin release in the poststimulatory period $(p=0.09, n=6)$. During phentolamine infusion $(p=0.003, n=6)$ and coinfusion of both atropine and phentolamine $(p=0.001, n=16)$, electrical nerve stimulation stimulated somatostatin output to $163.5(17.5) \%$ and $257.8(52.8) \%$ of basal

B

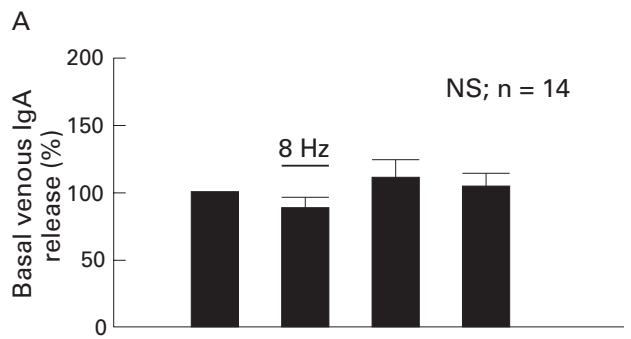

B
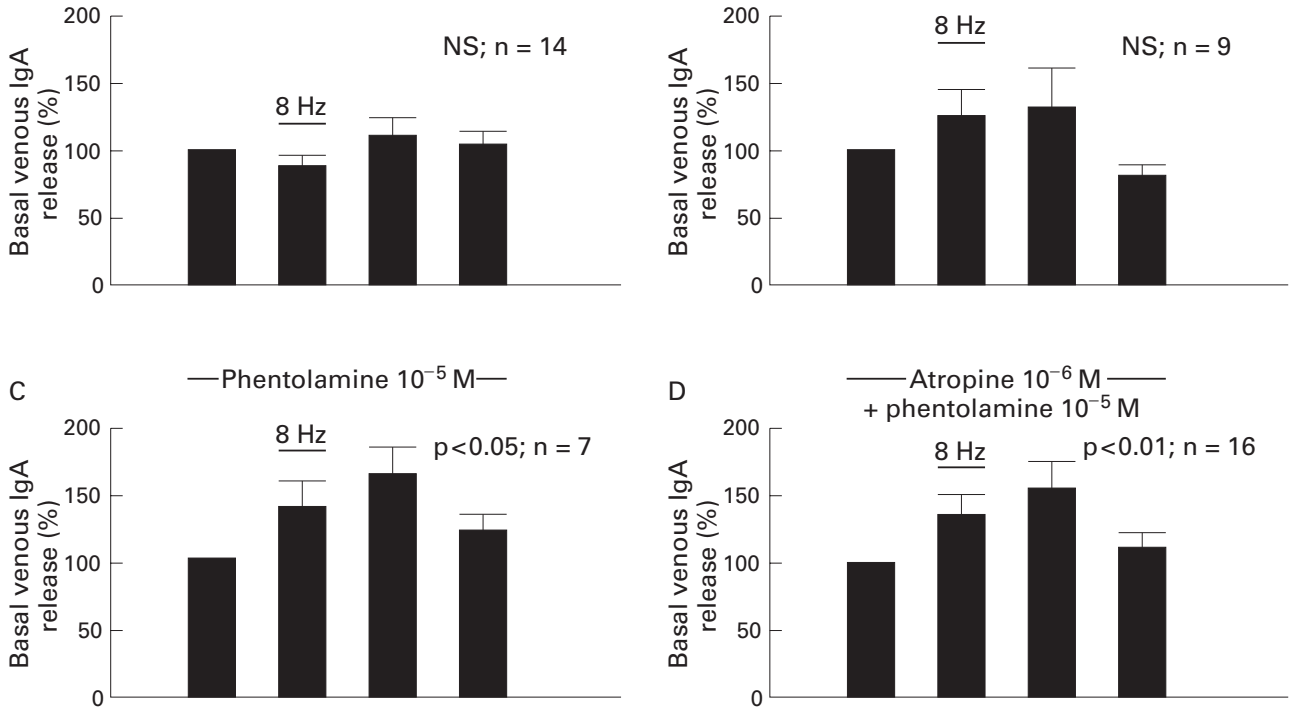

Figure 4 Effect of electrical stimulation of the extrinsic nerves at $8 \mathrm{~Hz}$ on the release of IgA to the venous effluent under basal conditions and during infusion of different receptor antagonists, expressed as percentage of basal release. Results expressed as mean (SEM). The four bars represent the prestimulatory, stimulatory, and two poststimulatory five minute periods. 


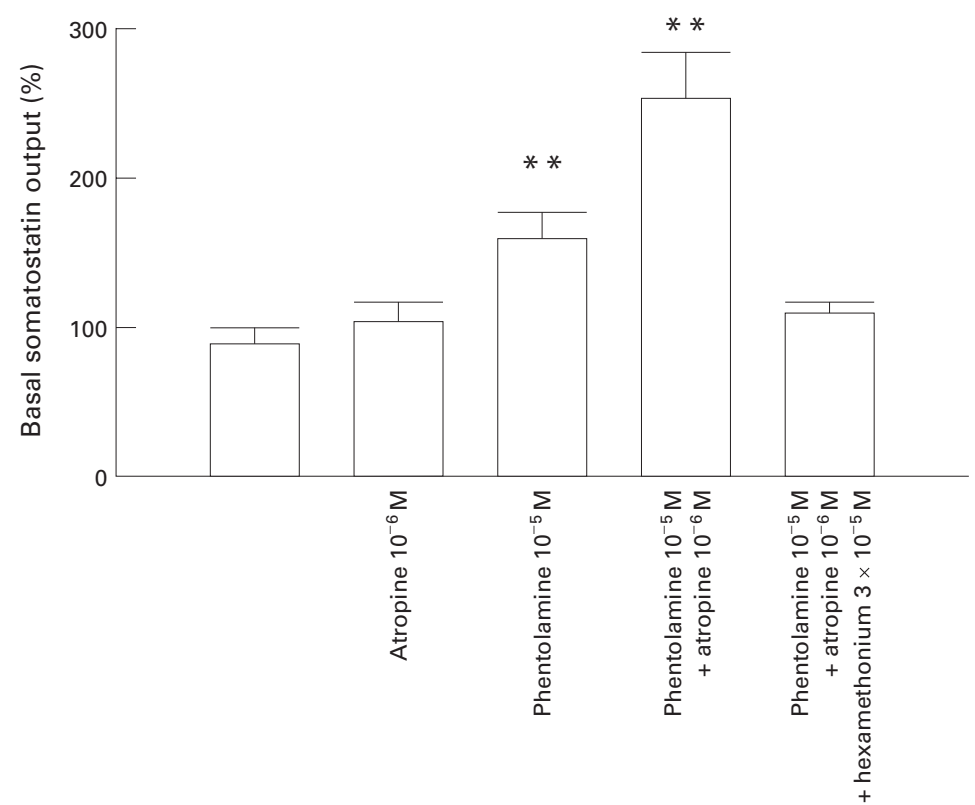

Figure 5 Effect of electrical stimulation of the extrinsic nerves at $8 \mathrm{~Hz}$ during infusion of different receptor antagonists on somatostatin release to the venous effluent. Results expressed as mean (SEM). ${ }^{\star *} p<0.01$.

release, respectively. Addition of hexamethonium abolished the stimulatory effect of nerve stimulation seen during coinfusion of atropine and phentolamine.

PERFUSION PRESSURE

Basal perfusion pressure was 40.9 (1.9) $\mathrm{mm}$ $\mathrm{Hg}(\mathrm{n}=11)$, and this was decreased by SP (to $96.8(4.4) \%$ of basal perfusion pressure; $\mathrm{p}=0.03, \mathrm{n}=11$ ), by capsaicin (to $88.1(11.1) \%$; $\mathrm{p}=0.001, \mathrm{n}=6$ ), and by VIP (to $89.2(6.6) \%$; $\mathrm{p}=0.001, \mathrm{n}=9)$. Noradrenaline significantly increased perfusion pressure to 140.0 (11.4)\% $(\mathrm{p}=0.03, \mathrm{n}=6)$ of basal pressure, but acetylcholine, somatostatin, CGRP, and NKA were all without effect.

Electrical nerve stimulation caused a marked increase in perfusion pressure to 141.4 (5.9)\% $(\mathrm{p}=0.001, \mathrm{n}=14)$, of basal pressure, an effect that was not affected by atropine, but inhibited by infusion of phentolamine (110.9 (1.7)\%; $\mathrm{p}=0.003, \mathrm{n}=7)$. During combined infusion of atropine and phentolamine, perfusion pressure only showed a small increase during electrical nerve stimulation (109.1 (1.9)\%;n=16), which was further reduced by addition of hexamethonium $(103.9(3.8) \% ; \mathrm{p}=0.02, \mathrm{n}=9)$.

\section{Discussion}

In the present study, the release of IgA was measured in both the luminal and venous effluent of porcine small intestinal segments perfused in vitro. The luminal effluent was collected from the distal part of the segment whenever an emptying of the luminal contents occurred. Under basal conditions spontaneous distal emptying was seen every two to three minutes. This was a consequence of the rather high luminal perfusion rate deliberately used in these experiments in order to increase the frequency of emptying so as to improve the temporal resolution of IgA secretory dynamics. During administration of agents that inhibit motility (VIP, noradrenaline, and electrical nerve stimulation ${ }^{14}$ ), the emptying rate decreased or ceased, thereby causing the temporal relation between actual IgA release and measured IgA release in the luminal perfusate to be perturbed. It is, therefore, difficult or impossible to evaluate the effects of inhibitory agents based on the output in the luminal effluent. Effects of SP and somatostatin, both of which stimulated motility, could be evaluated from determinations in both luminal and venous effluents, whereas the effects of the other stimuli are reported only in terms of venous release of IgA. The release of $\operatorname{IgA}$ was significantly increased in both the luminal and venous effluent in response to infusion of somatostatin, and a similar stimulation was seen in response to SP infusion. Although the release by the venous route amounted to only $0.6 \%$ of the luminal release, it seemed to parallel accurately the luminal release and may, therefore, be taken as an index of the total release during administration of stimuli inhibiting motility, where the luminal emptying rate may not parallel actual secretion.

The influence of the extrinsic nerves was studied using electrical stimulation of the mixed periarterial nerve fibres supplying the intestinal segment. Antagonists related to the peripheral sympathetic and parasympathetic nervous system were used to distinguish between the contribution of the two systems to the response of stimulation of the mixed nerve supply. Electrical stimulation of the extrinsic nerves significantly stimulated secretion of $\operatorname{IgA}$ only during blockade of $\alpha$ adrenergic receptors, muscarinic receptors, or both. The stimulatory effect seen during blockade of both $\alpha$ adrenergic and muscarinic receptors was abolished by blockade of nicotinic receptors.

Several neuropeptides stimulated IgA secretion and could thus be contributing to the effects of electrical stimulation of the extrinsic nerves. The extrinsic nervous control of the different neuropeptide releasing neurones in isolated ileal segments exhibits distinct differences. The tachykinins, SP and NKA, are released during electrical stimulation of the extrinsic nerves only when both $\alpha$ adrenergic and muscarinic receptors are blocked, ${ }^{14}$ whereas the release of VIP is inhibited during electrical nerve stimulation, but increased in the presence of phentolamine. When both atropine and phentolamine are infused, nerve stimulation has no effect on VIP release. ${ }^{15}$ Somatostatin is released during nerve stimulation when $\alpha$ adrenergic receptors or both $\alpha$ adrenergic and muscarinic receptors are blocked, as shown in this study. However, tachykinins do not seem to be mediating the release of IgA during electrical stimulation as they are not released in the same pattern as $\operatorname{IgA}$. Somatostatin, on the other hand, is released in the same pattern as IgA and is therefore a potential mediator of the neural control of IgA output. However, whether somatostatin is actually mediating this control cannot be established until antagonists for somatostatin receptors become available. The release pattern of CGRP during electrical 
nerve stimulation is different from the pattern of IgA secretion (Rasmussen, Schmidt, and Holst, unpublished results). Thus, the release of CGRP is strongly stimulated during electrical stimulation without infusion of receptor antagonists; it is therefore unlikely that CGRP is mediating the IgA release. The stimulatory effect of nerve stimulation during blockade of both $\alpha$ adrenergic and muscarinic receptors was abolished by hexamethonium, indicating that acetylcholine may be involved as a preganglionic neurotransmitter acting on nicotinic receptors. On the other hand, acetylcholine had no effect in itself, indicating that preganglionic activation at nicotinic receptors is not sufficient to cause release of IgA. However, it could be that acetylcholine, in addition to stimulating preganglionic nicotinic receptors, also inhibits IgA release by activation of muscarinic receptors. During electrical nerve stimulation, adrenergic nerves causing inhibition of IgA output seemed to be activated, as $\alpha$ adrenergic receptors had to be blocked before electrical nerve stimulation would cause an increase in IgA output, and infusion of noradrenaline strongly inhibited IgA output.

The mechanisms causing the actual extrusion of IgA to the gut lumen in response to activation of extrinsic nerves could be several. In the rat small intestine, it has been shown that the stimulatory effect of cholecystokinin and pilocarpine on IgA secretion is mediated by stimulation of electrolyte and water secretion pulling IgA and albumin into the lumen by solvent drag. ${ }^{21}$ This, however, cannot be a general mechanism for the different stimuli augmenting IgA secretion in pig small intestine, as VIP had no effect on IgA secretion although it strongly stimulates secretion of electrolytes and water. ${ }^{22}$ Alternatively, transepithelial transport of IgA could somehow be enhanced in a specific manner, although this cannot explain the increased output of $\operatorname{IgA}$ to the venous effluent.

Another mechanism could be vasodilatation induced by the neurotransmitters released in response to nerve stimulation. Increased blood flow to the IgA secreting cells in response to vasodilatation could favour IgA output. Evidence in favour of this mechanism is the fact that both SP and CGRP are strong vasodilators and stimulate IgA secretion, and noradrenaline is a strong vasoconstrictor and inhibits IgA output. On the other hand, this mechanism cannot be general as both VIP and capsaicin are also strong vasodilators, but had no effect on IgA secretion.

Motility is stimulated by several of the stimuli which also induce secretion of IgA, including SP, NKA, CGRP, and somatostatin. IgA output could be augmented by motility "squeezing" the mucosa. However, acetylcholine strongly stimulates intestinal motility, but had no effect on IgA secretion, implying that motility cannot be a general mechanism for neurally induced IgA secretion. During infusion of somatostatin and SP, not only the total output of IgA in the luminal effluent, but also the concentration of IgA increased, supporting the hypothesis that motility is not the sole mechanism causing increased IgA output.

Finally, it is possible that released neurotransmitters act directly on the IgA secreting plasma cells. The finding of receptors for neuropeptides on plasma cells supports this hypothesis. $^{823-25}$ Furthermore, there is anatomical evidence for a direct effect of neurotransmitters on plasma cells. The lamina propria in feline (and porcine) small intestine contains a large number of somatostatin immunoreactive nerve fibres, some of which are found close to plasma cells. ${ }^{9}$ The effects of extrinsic nerve stimulation could thus be mediated by neurotransmitters released close to plasma cells harbouring neurotransmitter receptors.

Although the transmitters involved in the extrinsic control of IgA release cannot be fully established from this study, it seems that sympathetic innervation inhibits the release as noradrenaline inhibited release of $\operatorname{IgA}$ and $\alpha$ adrenergic blockade augmented IgA release during electrical nerve stimulation. A parasympathetic regulation also seems to exist. Cholinergic nerves activating muscarinic receptors may have an inhibitory function, whereas cholinergic, probably preganglionic nerves activating postganglionic nerves via nicotinic receptors stimulate IgA release. As discussed, somatostatin could act as a final or intermediate transmitter. Sensory nerve fibres do not seem to be involved in the control of IgA as capsaicin had no effect on IgA release.

The technical assistance of Sørn Haagen Nielsen, Letty Klarskov, Mette Olesen, and Anni Mehlsen is gratefully acknowledged. This work was supported by grants from the Beckett Fonden, Fonden til Lægevidenskabens Fremme, and Michaelsen Fonden.

1 Bellinger DL, Lorton D, Felten SY, et al. Innervation of lymphoid organs and implications in development, aging, and autoimmunity. Int f Immunopharmacol 1992;14:329-44.

2 Pascual DW, Bost KL, Xu-amano J, et al. The cytokinin-like action of substance P upon B cell differentiation. Reg Immunol 1992;4:100-4.

3 Helme RD, Eglezos A, Dandie GW, et al. The effect of substance $\mathrm{P}$ on the regional lymph node antibody response to antigenic stimulation in capsaicin-pretreated rats. 7 Immuantigenic stimulation in

4 Boirivant M, Fais S, Annibale B, et al. Vasoactive intestinal polypeptide modulates the in vitro immunoglobulin production by intestinal lamina propria lymphocytes. Gastroenterology 1994;106:576-82.

5 Carucci JA, Herrick CA, Durkin HG. Neuropeptidemediated regulation of hapten-specific IgE responses in mice. II. Mechanisms of substance P-mediated isotypespecific suppression of BPO-specific IgE antibody forming cell responses induced in vitro. $\mathcal{F}$ Neuroimmunol 1994;49: $89-95$.

6 Stanisz AM, Befus D, Bienenstock J. Differential effects of vasoactive intestinal peptide, substance $P$, and somatostatin on immunoglobulin synthesis and proliferations by lymphocytes from Peyer's patches, mesenteric lymph nodes, and cytes from Peyer's patches, mesent
spleen. F Immunol 1986;136:152-6.

7 Ichikawa S, Spreedharan SP, Goetzl EJ, et al. Immunohistochemical localization of peptidergic nerve fibers and neuropeptide receptors in Peyer's patches of the cat ileum. Regul Pept 1994;54:385-95

8 Stanisz AM, Scicchitano R, Dazin P, et al. Distribution of substance P receptors on murine spleen and Peyer's patch $\mathrm{T}$ and $\mathrm{B}$ cells. F Immunol 1987;139:749-54.

9 Fehér E, Fodor M, Burnstock G. Distribution of somatostatin-immunoreactive nerve fibres in Peyer's patches. Gut 1992;33:1195-8.

10 Ader R, Cohe N, Felten DL. Brain, behaviour and immunity. Brain Behav Immun 1987;18:1-6.

11 Furness JB, Costa M. The enteric nervous system. New York: Churchill Livingstone, 1987.

12 Freier S, Eran M, Faber J. Effect of cholecystokinin and its antagonists, of atropine, and of food on the release of immunoglobulin A and immunoglobulin G specific antibodies in the rat intestine. Gastroenterology 1987;93:1242-6. 
13 Wilson ID, Soltis RD, Olson RE, et al. Cholinergic stimulation of immunoglobulin A secretion in rat intestine. Gastrotion of immunoglobulin A
enterology 1982;83:881-8.

14 Schmidt P, Rasmussen TN, Holst JJ. Nervous control of release of substance $\mathrm{P}$ and neurokinin $\mathrm{A}$ from the isolated perfused porcine ileum. F Auton Nerv Syst 1992;38:85-96.

15 Messel T, Harling H, Poulsen SS, et al. Extrinsic control of the release of galanin and VIP from intrinsic nerves of isolated, perfused, porcine ileum. Regul Pept 1992;38:179-98.

16 Holst JJ. Isolated organs as replacements for vertebrate animals. In: Svendsen P, Hau J, eds. Handbook of laboratory animal science. Vol 1. Selection and handling of animals in biomedical research. Boca Raton, FL: CRC Press, 1994:397408.

17 Schmidt P, Rasmussen TN, Holst JJ. Release of immunoreactive somatostatin, vasoactive intestinal polypeptide (VIP), and galanin during propulsive complexes in isolated ileum. Peptides 1993;14:215-20.

18 Rasmussen TN, Bersani M, Schmidt P, et al. Isolation and molecular characterization of porcine calcitonin genemolecular characterization of porcine calcitonin generelated peptide (CGRP) and its endocrine
porcine pancreas. Pancreas 1998;16:195-204.

19 Loftager M-K, Eriksen L, Nielsen R. Antibodies against Actinobacillus pleuropneumonia serotype 2 in mucosal secretions and sera of infected pigs as demonstrated by an enzyme-linked immunosorbent assay. Res Vet Sci 1993;54: $57-62$.

20 Hilsted L, Holst JJ. On the accuracy of radioimmunological determination of somatostatin in plasma. Regul Pept 1982; 4:13-31.

21 Freier S, Eran M, Alon Y, et al. Verapamil and furosemide prevent cholecystokinin-induced translocation of immunoglobulins in rat intestine. Dig Dis Sci 1991;36:1619-24.

22 Thorbøll JE, Bindslev N, Tindholdt TT, et al. Tachykinins mediate changes in ion transport in porcine jejunum through the release of prostaglandins and neurotransmitters. Regul Pept 1998;77:105-11.

23 Kimata H, Yoshida A, Ishioka C, et al. Vasoactive intestinal peptide enhances immunoglobulin production and growth in human plasma cells via mechanisms that may involve protein kinase C. 7 Clin Endocrinol Metab 1996;81:3024-32.

24 Hartung H-P, Wolters K, Toyka KV. Substance P: binding properties and studies on cellular responses in guinea pig macrophages. F Immunol 1986;136:3856-63.

25 Calvo JR, Montilla ML, Guerrero JM, et al. Expression of VIP receptors in mouse peritoneal macrophages: functional and molecular characterization. $\mathcal{f}$ Neuroimmunol 1994;50:85-93. 